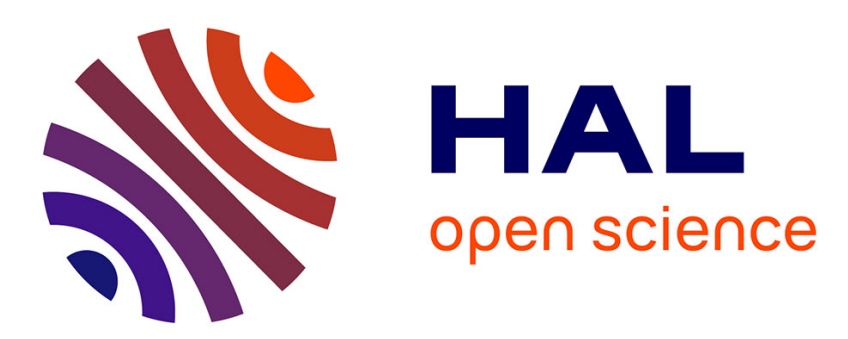

\title{
Explosive properties of superheated aqueous solutions in volcanic and hydrothermal systems
}

Régis Thiery, Sébastien Loock, Lionel Mercury

\section{To cite this version:}

Régis Thiery, Sébastien Loock, Lionel Mercury. Explosive properties of superheated aqueous solutions in volcanic and hydrothermal systems. Metastable Systems under Pressure, Springer, pp.293-310, 2010. insu-00460799

\section{HAL Id: insu-00460799 \\ https://hal-insu.archives-ouvertes.fr/insu-00460799}

Submitted on 12 Mar 2010

HAL is a multi-disciplinary open access archive for the deposit and dissemination of scientific research documents, whether they are published or not. The documents may come from teaching and research institutions in France or abroad, or from public or private research centers.
L'archive ouverte pluridisciplinaire HAL, est destinée au dépôt et à la diffusion de documents scientifiques de niveau recherche, publiés ou non, émanant des établissements d'enseignement et de recherche français ou étrangers, des laboratoires publics ou privés. 
Châpitre d’ouvrage : Metastable Systems under Pressure

\title{
Explosive properties of superheated aqueous solutions in volcanic and hydrothermal systems.
}

\author{
RÉGIS THIÉRY ${ }^{1}$, \\ SÉBASTIEN LOOCK ${ }^{1,2}$ \\ LIONEL MERCURY ${ }^{3}$ \\ ${ }^{1}$ Laboratoire Magmas et Volcans, UMR 6524, CNRS/Clermont \\ Université/OPGC, 5, rue Kessler, 63038 Clermont-Ferrand, France. \\ ${ }^{2}$ Laboratoire Géoazur, 250 rue Albert Einstein, 06560 Valbonne, \\ France. \\ ${ }^{3}$ Institut des Sciences de la Terre d'Orléans, Université d'Orléans, UMR \\ 6113 CNRS-INSU, 1 A rue de la Férollerie, 45071 Orléans, France.
}

\begin{abstract}
Superheated aqueous solutions in volcanic and hydrothermal environments are known to reequilibrate violently through explosive boilings and gas exsolutions. While these phenomena are purely kinetic problems in essence, the explosivity conditions of these demixion processes can be investigated by following a thermodynamic approach based on spinodal curves. In a first part, we recall briefly the concepts of mechanical and diffusion spinodals. Then, we propose to differentiate superspinodal (explosive) transformations from subspinodal (non-explosive) ones. Finally, a quantitative study of spinodal curves is attempted on the binary systems $\mathrm{H}_{2} \mathrm{O}-\mathrm{CO}_{2}$ and $\mathrm{H}_{2} \mathrm{O}-\mathrm{NaCl}$ with equations of state with solid theoretical basis. It is shown that dissolved gaseous components and electrolytes have an antagonist effect: dissolved volatiles tend to shift the superspinodal region towards lower temperatures, whereas electrolytes tend to extend the metastable field towards higher temperatures. This study may give some clues to understand the explosive destabilization conditions of aqueous solutions in phreatic, phreato-magmatic and hydrothermal eruptions.
\end{abstract}

Key Words: metastability, equation of state, spinodal, explosivity, aqueous solution, carbon dioxide, sodium chloride, supersaturation, natural systems.

\section{Introduction}

Water is the main natural explosive agent on the Earth. This fact is well demonstrated by all forms of volcanic and hydrothermal explosive manifestations, characterized by a sudden and brutal vaporization of water and other dissolved volatiles from a condensed state, either from aqueous solutions or from supersaturated magmas ${ }^{1}$. This paper is mainly devoted to the first case, i.e. the explosivity of aqueous solutions. Explosions can be defined as violent reactions of systems, which have been perturbed up to transient and unstable states by physico-chemical processes. As such, the traditional approach to such 
problems is to rely on kinetic theories of bubble nucleations and growths, and this topic has been already the subject of an abundant literature (see references therein ${ }^{2-3}$ ). We apply here an alternative and complementary method by following a phenomenological thermodynamical point of view. Indeed, an explosive situation is obtained when a boiling transformation perturbs a liquid up to near or through a thermodynamic frontier, i.e., a spinodal, delimiting a thermodynamically forbidden and unstable region of the phase diagram of the system. In a first part, the theoretical grounds of this paradigm are briefly justified, and it will be shown how boilings and gas exsolutions can be differentiated, depending upon the process conditions, either in explosive transformations or non-explosive ones. Then, these concepts will be exploited on two important types of aqueous solutions, which are the $\mathrm{H}_{2} \mathrm{O}-\mathrm{CO}_{2}$ and the $\mathrm{H}_{2} \mathrm{O}$ $\mathrm{NaCl}$ systems. This thermodynamic modeling will use equations of state built on solid physical bases, which will allow us to decipher the thermodynamic factors controlling the explosivity of boiling and gas exsolution of aqueous solutions in volcanic and hydrothermal environments ${ }^{1}$.

\section{Theoretical concepts of explosivity}

The key to an explosive transformation is not the level of mechanical work yielded to the environment, but the rate of mechanical energy release. This latter parameter features the power or yield of the explosion. The higher is this quantity, the stronger are the damages around the explosion focus in terms of fragmentation and other blast effects. In other words, explosive processes are characterized by kinetic rates, which are significantly more elevated by several magnitude orders than in near-equilibrium processes. Therefore, such explosive phenomena can be produced only in strongly disequilibrated systems. Interestingly, the disequilibrium degree of a system can be estimated with the help of the second principle of thermodynamics, which gives us stability criteria that any system must obey ${ }^{2,4}$. The first one is the mechanical stability criterion, which states that any isothermal volume $(V)$ increase of a system must result to a decrease of its internal pressure $(P)$ :

$$
\left(\frac{\partial P}{\partial v}\right)_{T} \leq 0 .
$$

The second one is the diffusion stability criterion, which imposes the net and spontaneous diffusion (i.e. in the absence of any external forces) of species from concentrated regions to less concentrated ones. This criterion is formulated by:

$$
\left(\frac{\partial^{2} G}{\partial x_{i}^{2}}\right)_{T, P, x_{j}} \geq 0,
$$

where $G$ is the Gibbs free energy and $x_{i}$ refers to the diffusing species in a fluid mixture. The limiting conditions, i.e. when the above quantities are nil, are of interest, as they characterize highly unstable systems. The locus curves of 
$(\partial \mathrm{P} / \partial)_{T}=0$ and $\left(\partial^{2} G / \partial x^{2}\right)_{T, P, x_{j}}=0$ can be projected onto any phase diagram and correspond to thermodynamic frontiers separating metastable and unstable domains. The first locus curve refers to the so-called mechanical spinodal curve, whereas the second one is the diffusion spinodal curve $e^{4,5}$. Spinodal curves represent the highest disequilibrium degrees, which can be reached by a fluid before its brutal and rapid demixion. Hence, the explosivity of a physical transformation can be assessed, at least qualitatively, by considering the incursion degree of a liquid through its metastable region up to its thermodynamically forbidden domain of instability.

\section{Discussion and application to pure water}

The paradigm presented in the preceding section can be applied to the case of pure water. Figure 1 shows the stability, metastability and instability fields for water in a pressure-temperature plot, as calculated by the Wagner and Pruss equation of state ${ }^{6}$. Only the mechanical stability criteria is relevant to this onecomponent system. Limiting stability conditions are encountered along the liquid spinodal curve, noted $\mathrm{Sp}(\mathrm{L})$, and along the gas spinodal curve, noted $\mathrm{Sp}(\mathrm{G})$. Both spinodal curves meet at the critical point CP with the liquid-gas (LG) saturation curve (also called binodal). The gas spinodal curve indicates the theoretical extreme conditions, which can be attained by a metastable gas (referred to as a supercooled gas). In the other way, the liquid spinodal curve marks the furthest theoretical conditions reachable by a metastable liquid (or superheated liquid) before its explosive demixion into a liquid-gas mixture. Figure 1 depicts also the two main physical processes, which can trigger the boiling of a liquid: these are (1) isobaric boiling and (2) adiabatic decompression (which can be approximated as a quasi-isothermal process for a liquid).

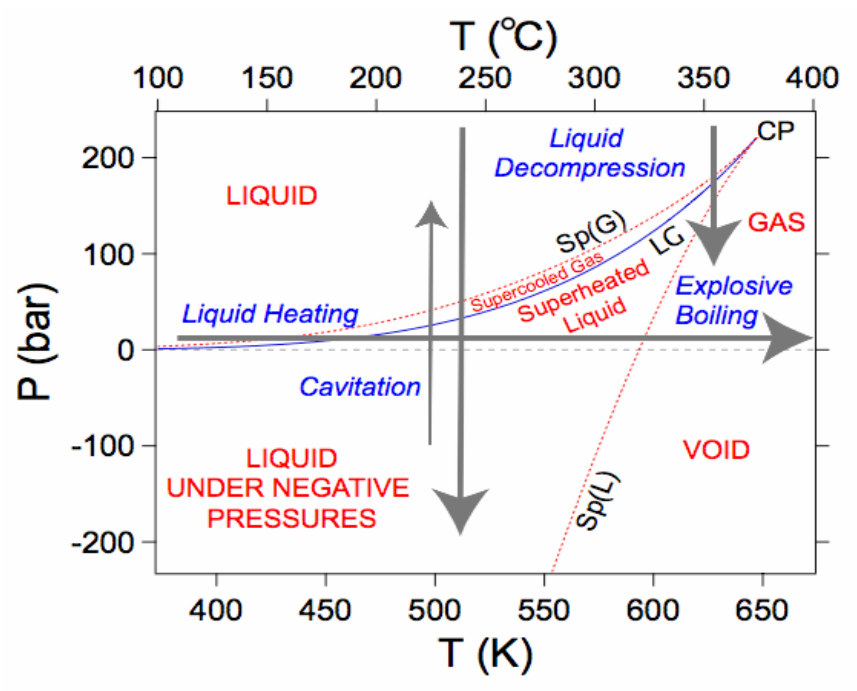


Fig. 1. Pressure-temperature diagram illustrating the different perturbation processes of liquid water, and their relations with the stable, metastable and unstable fields of $\mathrm{H}_{2} \mathrm{O}$. Solid line: the saturation curve (LG). Dotted lines: the mechanical liquid spinodal curve $\mathrm{Sp}(\mathrm{L})$ and the mechanical gas spinodal curve $\mathrm{Sp}(\mathrm{G})$.

In practice, spinodal states of liquid-gas transitions cannot be studied experimentally (at the notable exception of the critical point, which is both a gas and liquid spinodal point). The lifetime of a metastable fluid decreases drastically at the approach of a spinodal curve ${ }^{7}$. Thus, rapid processes, e.g. a very quick heating step or a sudden decompression (Fig. 1), are able to transport a liquid up to spinodal conditions. Energetic barriers of nucleations decrease then to the same magnitude order than molecular fluctuations. Thus, bubble nucleations become active and spontaneous mechanisms, contrasting to the case of weak supersaturation or superheating degrees, where the nucleations of bubbles are known to be a slow process, which must be activated to occur. Kiselev ${ }^{8}$, and Kiselev and Ely ${ }^{9}$ have calculated precisely the pressure-temperature conditions of this change of nucleation regime for water, introducing the notion of kinetic spinodal. This curve mimics the trend of thermodynamic liquid spinodal curve (but is shifted to lower temperatures in a pressure-temperature plot). Moreover, experimental studies of liquid-liquid demixing in alloys or polymers, as well numerical simulations, have demonstrated that the usual matter separation of nucleation-phase growth is replaced by the faster and more efficient process of spinodal decomposition ${ }^{2,10}$ in the instability domain. Hence, the approach of a superheated liquid up to spinodal conditions is synonym for explosive vaporization.

This paradigm has been validated by the analysis of numerous industrial explosions. A first type of explosions is caused by the sudden depressurization of liquids. In the specialized litterature, this phenomenon is commonly referred to as a BLEVE ${ }^{11-16}$ (acronym for a Boiling Liquid Expansion Vapour Explosion). Another type of explosions is produced by the fortuitous contact of a liquid with a hot body at the origin of FCI (Fuel Coolant Interactions) or MFCI (Molten Fuel Coolant Interactions) explosions ${ }^{17-19}$. In each of these categories (BLEVE and FCI), the explosions are interpreted to result mainly from the destabilization of a fluid at near-spinodal conditions. A schematic illustration is given in Fig. 2 in the case of a sudden liquid decompression. The initial state is a liquid at some temperature $T 0$ and pressure $P 0$, well above the external pressure. The vessel is opened at once, triggering a fast and adiabatic decompression of the liquid. The following depends upon the initial temperature TO. In the first case (left part of Fig. 2), the depressurization leads only to some bubble nucleations and produces moderate foaming of the liquid surface. In the second case (right part of Fig. 2), relevant to a BLEVE explosion, the opening of the tank is accompanied by a shock wave, and possibly by its failure with emission of projectiles. The boiling proceeds here by active spontaneous bubble nucleations, or conceivably by spinodal decomposition in the case of very high depressurization rates. The 
thermodynamic interpretation of these two different evolutions is given in the bottom part of Fig. 2, and involves the spinodal temperature $T_{s p}$ at ambient pressure $\left(T_{s p}=320.45^{\circ} \mathrm{C}=593.6 \mathrm{~K}\right.$ for pure water at one bar, as calculated by the Wagner and Pruss equation of state $\left.{ }^{1,6}\right)$. In the first case, the adiabatic decompression occurs at a temperature below $T_{s p}$ : the depressurization path does not cut the liquid spinodal curve $\mathrm{Sp}(\mathrm{L})$ and no explosion occurs. In the second case, the liquid spinodal curve $\mathrm{Sp}(\mathrm{L})$ is intersected by the adiabatic depressurization path, as the decompression occurs at a temperature above $T_{s p}$, triggering a large-scale explosion. Therefore, we suggest to introduce the terms of subspinodal for non-explosive transformations, and superspinodal for the case of explosive ones.

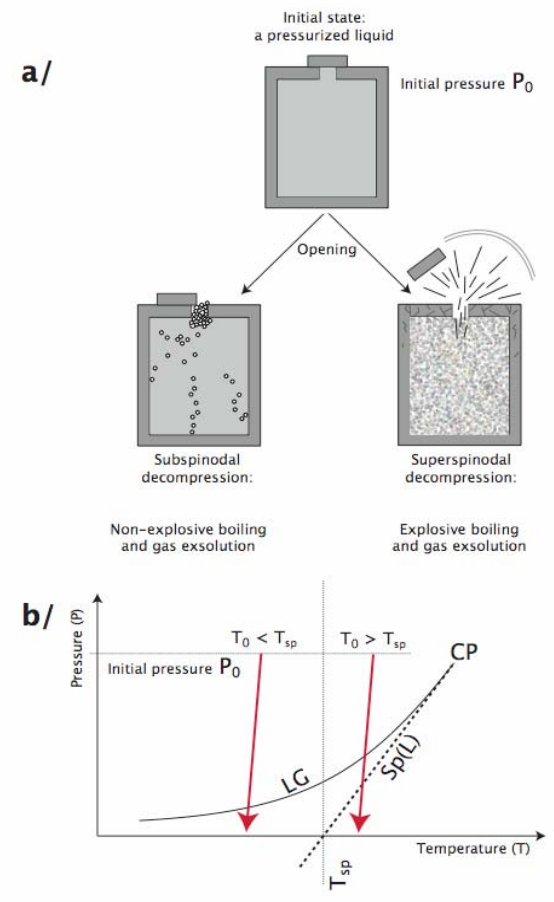

Fig. 2. a/ Schematic illustration of a subspinodal (left) and a superspinodal depressurization (right). b/ Thermodynamic interpretation of the transformation explosivity in a pressure-temperature diagram.

Note that this interpretation should not be applied too restrictively. Experience shows that some explosive boilings can already occur at temperatures below $T_{s p}{ }^{16}$. The spinodal temperature $T_{s p}$ is a pure thermodynamical concept, and the temperature $T_{h n}$ of homogeneous nucleation ${ }^{1,2}\left(T_{h n}=304^{\circ} \mathrm{C}, 577 \mathrm{~K}\right.$ at one bar for pure water), which is a kinetic parameter, could be more appropriate. 
Moreover, depending upon the circumstances, a decompression under subspinodal conditions does not always trigger boiling, and the solution becomes then supersaturated. In the case of a transient decompression in a confined system, cavitation (Fig. 1) can take place ${ }^{1}$.

Nevertheless, thermodynamics provides us with a simple concept which can help us to analyse the possible evolution, explosive or not, of a boiling or gas exsolution process. However, while the liquid spinodal curve of water is presumably well known, at least in its high-temperature part ${ }^{5}$, the topology of spinodal curves of aqueous solutions is poorly known. The purpose of the next two sections is to fill in this gap for $\mathrm{CO}_{2}$ and $\mathrm{NaCl}$ aqueous solutions.

\section{The $\mathrm{H}_{2} \mathrm{O}-\mathrm{CO}_{2}$ system}

The representation of spinodals is a highly demanding task for an equation of state, as calculations are done beyond their fitting range with experimental data. As a consequence, this requires a model with good extrapolation capabilities. The corollary is that we must restrict ourselves to equations of state with a good physical basis, and which do not rely on ill-founded empirical correlations. Moreover, the $\mathrm{H}_{2} \mathrm{O}-\mathrm{CO}_{2}$ system involves rather complex molecular interactions, which are not easy to describe rigorously ${ }^{20,21}$ : indeed, $\mathrm{H}_{2} \mathrm{O}$ is a strong dipolar molecule, which associates to neighboring water molecules through hydrogen bounds, whereas $\mathrm{CO}_{2}$ is a quadrupole. A first approximation is to use van der Waals like equations of state (the so-called cubic equations of state), but which incorporate into their attractive $a$ parameter the effects of hydrogen bounds, dipole-dipole and dipole-quadrupole interactions. A preliminary selection leads us to choose the Peng-Robinson-Stryjek-Vera (PRSV) equation of state ${ }^{22-24}$, which gives good results for mixtures of polar and nonpolar components ${ }^{25}$. A quadratic mixing rule with a zero binary interaction parameter between $\mathrm{H}_{2} \mathrm{O}$ and $\mathrm{CO}_{2}$ has been retained to describe the mixing properties of water and carbon dioxide. Therefore, results given here have to be considered as semi-quantitative. Nevertheless, they should give a reasonable idea of the topology of spinodal curves in water-gases systems. All calculations (thermodynamic properties, binodals, spinodals, critical curves) have been made with the help of the LOTHER library ${ }^{20,21,26}$ for fluid phase equilibria calculations.

Fig. 3A gives solubility curves and spinodals calculated by the PRSV equation of state at $323 \mathrm{~K}, 50^{\circ} \mathrm{C}$ in a pressure-mole fraction of $\mathrm{CO}_{2}$ diagram. For comparison, the solubility curve $\mathrm{L}(\mathrm{G})$ of $\mathrm{CO}_{2}$ in water, calculated by the more accurate model of Duan and $\mathrm{Sun}^{27}$, is also drawn and shows that the PRSV equation of state underestimates the $\mathrm{CO}_{2}$ solubility in water. The mechanical spinodal curves for the liquid, noted $\mathrm{mSp}(\mathrm{L})$, and for the gas, noted $\mathrm{mSp}(\mathrm{G})$ are plotted too with diffusion spinodal curves $\mathrm{Sp}(\mathrm{L})$ and $\mathrm{Sp}(\mathrm{G})$. The relations between spinodal curves can be observed more clearly on a molar volume-mole fraction of $\mathrm{CO}_{2}$ (Fig. 3B). Mechanical spinodal curves $\mathrm{mSp}(\mathrm{L})$ and $\mathrm{mSp}(\mathrm{G})$ meet at a pseudo-critical point (pCC) ${ }^{5,28}$. The diagram shows also that the mechanical 
instability field (and the pCC) is included in the diffusion instability domain. This result can be generalized and has been demonstrated by Imre and Kraska ${ }^{5}$. Thus, for mixtures, the relevant stability criterion is not the mechanical one, but the diffusion one.

The projections of the $\mathrm{L}(\mathrm{G})$ and $\mathrm{Sp}(\mathrm{L})$ isotherms in a $P-x_{\mathrm{CO} 2}$ diagam (Fig. 3A) are almost vertical and parallel. As a consequence, the depressurization of a $\mathrm{CO}_{2}$-supersaturated solution cannot perturb the fluid up to near-spinodal conditions: gas exsolution will always proceed only by moderate bubble nucleations and any decompression process will be subspinodal.
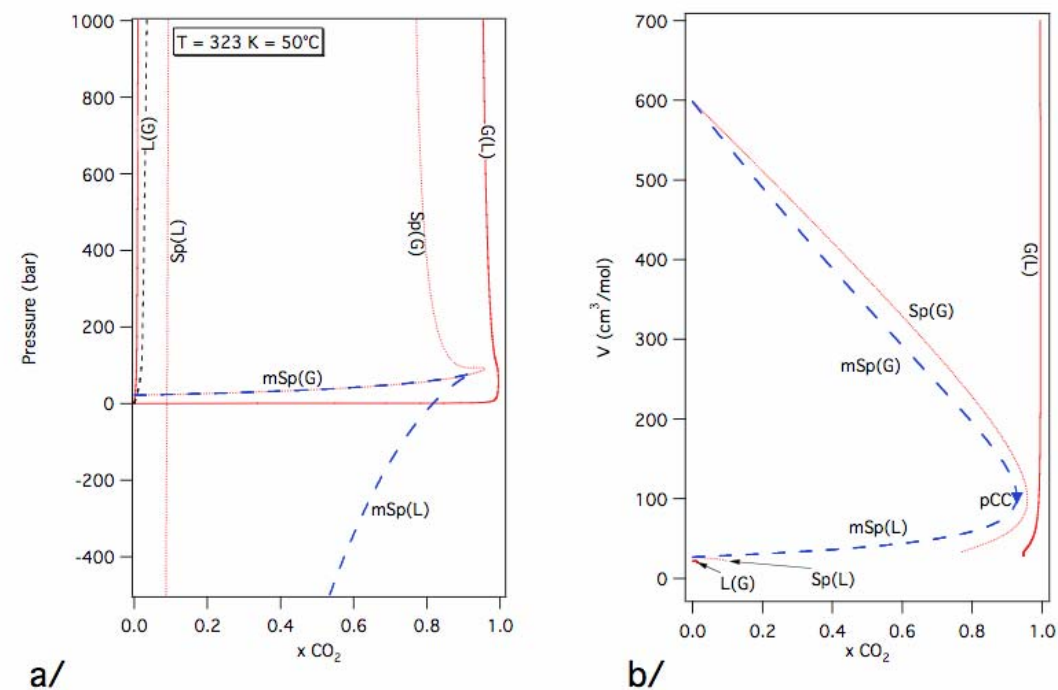

Fig. 3. a/ Pressure - $\mathrm{CO}_{2}$ mole fraction diagram showing the boundaries of stable, metastable and unstable fields, as calculated by the PRSV equation of state in the $\mathrm{H}_{2} \mathrm{O}-\mathrm{CO}_{2}$ system at $323 \mathrm{~K}, 50^{\circ} \mathrm{C}$. Solid lines: the solubility curve $\mathrm{L}(\mathrm{G})$ of $\mathrm{CO}_{2}$ in liquid water, the solubility curve $\mathrm{G}(\mathrm{L})$ of $\mathrm{H}_{2} \mathrm{O}$ in gaseous $\mathrm{CO}_{2}$. Dotted lines: the diffusion liquid $\mathrm{Sp}(\mathrm{L})$ and gas $\mathrm{Sp}(\mathrm{G})$ spinodal curves. Long dashed curves: the mechanical liquid $\mathrm{mSp}(\mathrm{L})$ and gas $\mathrm{mSp}(\mathrm{G})$ spinodal curves. Short dashed curve: solubility curve $\mathrm{L}(\mathrm{G})$ calculated by the Duan and Sun model ${ }^{27}$. b/ Molar volume- $\mathrm{CO}_{2}$ mole fraction diagram illustrating the relations between the diffusion and the mechanical metastable fields. Triangle marker: the pseudo-critical point (pCP) at $50^{\circ} \mathrm{C}$.

Superspinodal depressurizations are possible in the $\mathrm{H}_{2} \mathrm{O}-\mathrm{CO}_{2}$ system at much higher temperatures. An example is given in Fig. 4, where binodal and spinodal curves at $623 \mathrm{~K}, 350^{\circ} \mathrm{C}$ are plotted in a $P-x_{\mathrm{CO} 2}$ diagram. The four curves $L(G), G(L), S p(L)$ and $S p(G)$ join at one critical point $\mathrm{CP}$ of the $\mathrm{H}_{2} \mathrm{O}-\mathrm{CO}_{2}$ critical curve. Moreover, $\mathrm{L}(\mathrm{G})$ and $\mathrm{Sp}(\mathrm{L})$ curves are not spaced out. For example, a $\mathrm{CO}_{2}$ aqueous solution with $x_{\mathrm{CO} 2}=0.04$ at $350^{\circ} \mathrm{C}$ is saturated at $220 \mathrm{bar}$, but is already 
in a spinodal state at 195 bar. Therefore, any brutal decompression of a $\mathrm{CO}_{2^{-}}$ saturated solution should lead to a large scale destabilization at this temperature.

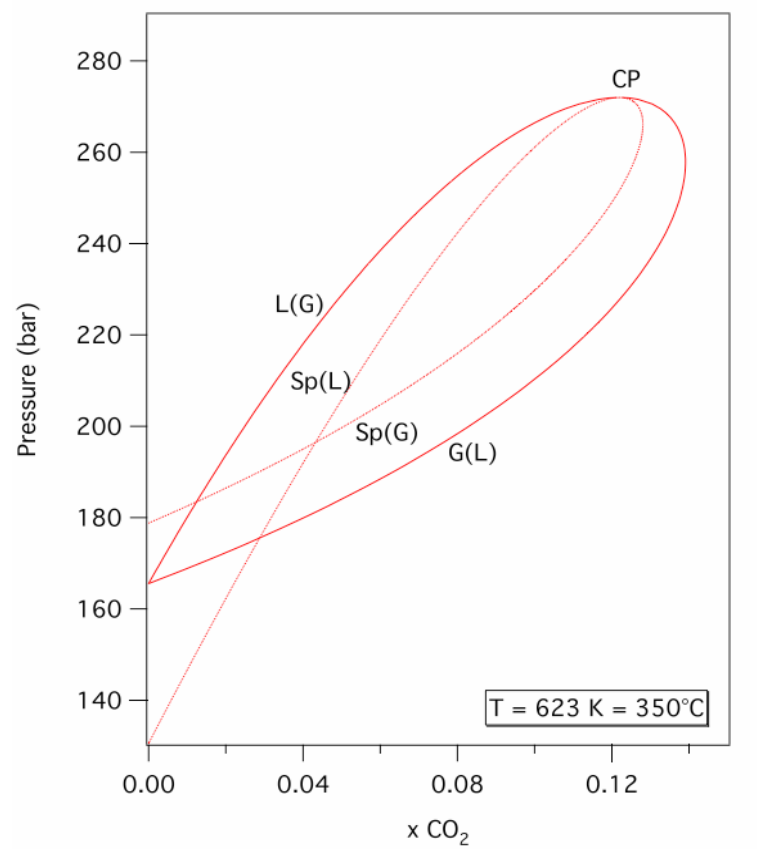

Fig. 4. Pressure- $\mathrm{CO}_{2}$ mole fraction diagram showing the extent of stable, metastable and unstable fields in the $\mathrm{H}_{2} \mathrm{O}-\mathrm{CO}_{2}$ system at $623 \mathrm{~K}, 350^{\circ} \mathrm{C}$.

Fig. 5 depicts the liquid spinodal curves $\mathrm{Sp}(\mathrm{L})$ in a pressure-temperature diagram for fixed $\mathrm{CO}_{2}$ compositions. The region of negative pressures, which is of interest for describing the capillary properties of $\mathrm{CO}_{2}$ aqueous solutions ${ }^{7}$, has been also included. Interestingly, it can be noted that spinodal $\mathrm{Sp}(\mathrm{L})$ isopleths present a pressure-temperature trend, which looks similar to the liquid spinodal curve of pure water ${ }^{1,2,6,7}$. At low temperatures, the $S p(L)$ isopleths are decreasing steeply before to reach a pressure minimum. Then at subcritical temperatures, isopleths are less spaced and sloped, and they finish to meet the $\mathrm{H}_{2} \mathrm{O}-\mathrm{CO}_{2}$ critical curve. The temperature appears as a determining parameter in the explosivity control of $\mathrm{CO}_{2}$ aqueous solutions. Like for water, the easiest way to generate an explosive vaporization is a sudden depressurization in the superspinodal domain, where spinodal curves have a gentle slope in a $P$ - $T$ diagram (Fig. 5). This superspinodal field can be estimated theoretically from the PRSV equation of state for temperature $T$ above $425 \mathrm{~K}\left(150^{\circ} \mathrm{C}\right)$, whose value is to be compared with the spinodal temperature $T_{s p}$ of pure water at 1 bar at $320.45^{\circ} \mathrm{C}^{1,6}$. Depressurizations are expected to be subspinodal below this temperature threshold, and superspinodal above. Therefore, the presence of dissolved volatiles in aqueous solutions reduces strongly their metastability field towards lower temperatures and accentuate their explosivity potential with respect to pure 
water. In the subspinodal region $\left(\mathrm{T}<150^{\circ} \mathrm{C}\right)$, a very fast and important $\mathrm{CO}_{2}$ dissolution is necessary to shift an aqueous solution from saturation conditions to spinodal ones: such a process seems to be unlikely.

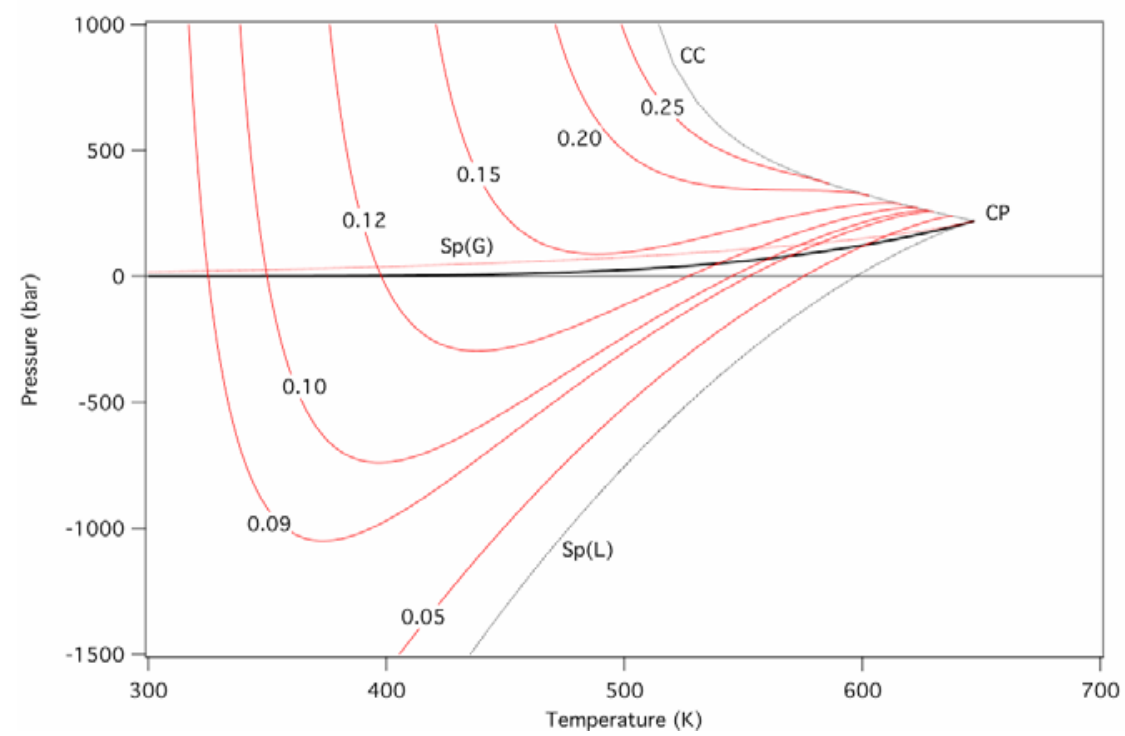

Fig. 5. The liquid spinodal curves in a pressure-temperature diagram for the $\mathrm{H}_{2} \mathrm{O}-\mathrm{CO}_{2}$ system, as calculated by the PRSV equation of state. Numbers refer to the mole fraction $x \mathrm{CO}_{2}$ of dissolved $\mathrm{CO}_{2}$ in the aqueous solution.

\section{The $\mathrm{H}_{2} \mathrm{O}-\mathrm{NaCl}$ system}

The same approach can be applied to investigate the explosivity conditions of the $\mathrm{H}_{2} \mathrm{O}-\mathrm{NaCl}$ system. We have selected the Anderko-Pitzer (AP) equation of state ${ }^{29}$, which is based on realistic physical hypotheses. It describes $\mathrm{H}_{2} \mathrm{O}-\mathrm{NaCl}$ by means of statistical thermodynamic models ${ }^{30,31}$ developed for dipolar hard spheres. This assumption is reasonable at high temperatures, where $\mathrm{NaCl}$ is known to form dipolar ion pairs. However, for this reason, this equation of state is only applicable above $573 \mathrm{~K}, 300^{\circ} \mathrm{C}$.

Fig. 6 displays a first $P-x_{\mathrm{NaCl}}$ diagram depicting binodal and spinodal isotherms at $623 \mathrm{~K}, 350^{\circ} \mathrm{C}$. The equation of state reproduces well the tabulated data by Bischoff ${ }^{32}$ for the solubility curves $L(G)$ and $G(L)$. The pressures of the diffusion spinodal curves $\mathrm{Sp}(\mathrm{L})$ and $\mathrm{Sp}(\mathrm{G})$ decrease with increasing $x_{\mathrm{NaCl}}$ mole fractions (note also that the spinodal curves run through the stability field of halite at pressures below 100 bars). As a consequence, the $\mathrm{H}_{2} \mathrm{O}-\mathrm{NaCl}$ system presents a dual behaviour concerning its stability during a rapid depressurization. For $x_{\mathrm{NaCl}}$ between 0 and 0.04 , a decompression path up to atmospheric pressures will intersect the liquid spinodal curve $\mathrm{Sp}(\mathrm{L})$ : this will trigger an explosive exsolution of $\mathrm{H}_{2} \mathrm{O}$ from the brine, featuring a superspinodal process. Differently, 
for higher $x_{\mathrm{NaCl}}$, the spinodal curve $\mathrm{Sp}(\mathrm{L})$ runs to negative pressures, and any brutal depressurization will generate only non-explosive boiling of the concentrated brines, characterizing a subspinodal transformation.

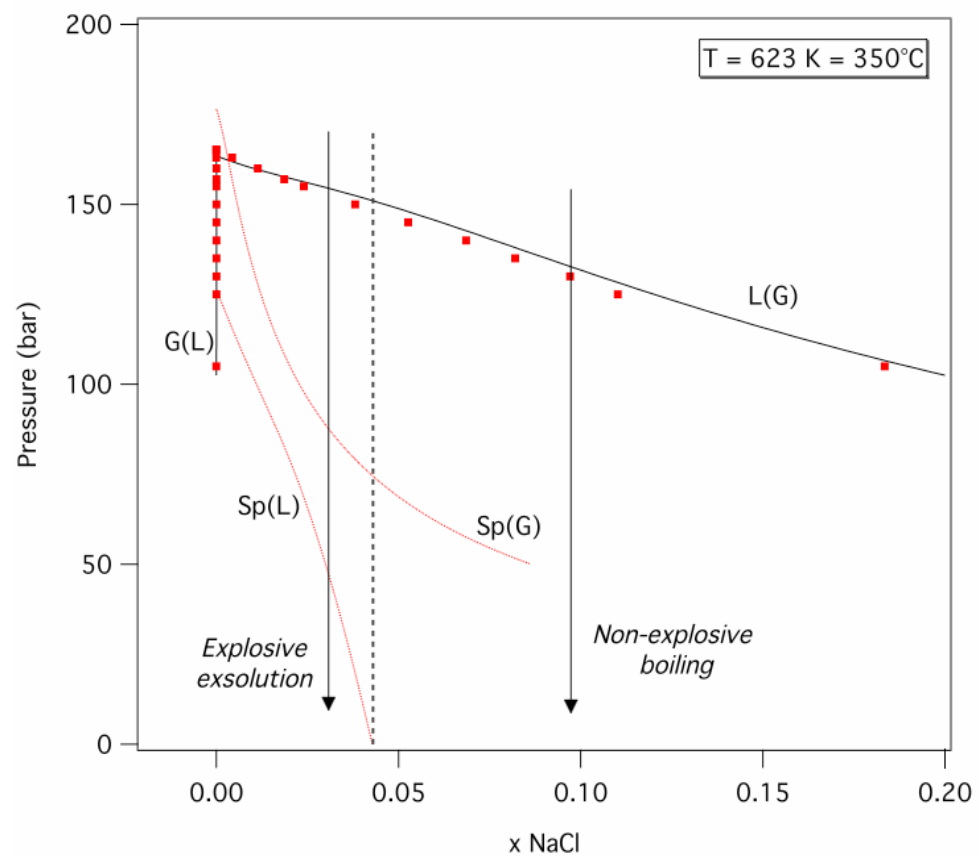

Fig. 6. The stable, metastable and unstable fields in a pressure- $\mathrm{NaCl}$ mole fraction diagram for the $\mathrm{H}_{2} \mathrm{O}-\mathrm{NaCl}$ system at $623 \mathrm{~K}, 350^{\circ} \mathrm{C}$, as calculated by the Anderko and Pitzer equation of state ${ }^{29}$. Solid lines: the solubility curves $\mathrm{L}(\mathrm{G})$ and $\mathrm{G}(\mathrm{L})$. Dotted lines: the spinodals $\mathrm{Sp}(\mathrm{L})$ and $\mathrm{Sp}(\mathrm{G})$. Squared markers: experimental data compiled by Bischoff ${ }^{29}$.

Two other portrays of the metastability fields of the $\mathrm{H}_{2} \mathrm{O}-\mathrm{NaCl}$ system are given in the $P-X_{\mathrm{NaCl}}$ diagrams of Fig. $7 \mathrm{~A}$ (at $380^{\circ} \mathrm{C}$ ) and Fig. $7 \mathrm{~B}\left(\right.$ at $500^{\circ} \mathrm{C}$ ), i.e. at temperatures above the critical point of $\mathrm{H}_{2} \mathrm{O}$. Now, both spinodal $\mathrm{Sp}(\mathrm{L})$ and $\mathrm{Sp}(\mathrm{G})$ isotherms join at a critical point $(\mathrm{CP})$. Another intersection point can be observed at lower pressures, but beware, this is only an artefact generated by the projection of spinodal isotherms onto $P-\chi_{\mathrm{NaCl}}$ planes. Again, $\mathrm{H}_{2} \mathrm{O}-\mathrm{NaCl}$ brines present the same contrasting behaviour, when they are submitted to a sudden depressurization. Below some $x_{\mathrm{NaCl}}$ threshold (e.g. for $x_{\mathrm{NaCl}}<0.08$ at $380^{\circ} \mathrm{C}$ and $x_{\mathrm{NaCl}}<0.19$ at $500^{\circ} \mathrm{C}$ ), fast decompressions will result to superspinodal vaporizations. Thus, subspinodal boilings concern only rather concentrated brines at these elevated temperatures. Note also that the metastability field of supercooled vapours (i.e. between the $G(L)$ and $S p(G)$ curves) extends over a non negligible range of pressures and $\mathrm{NaCl}$ compositions. 

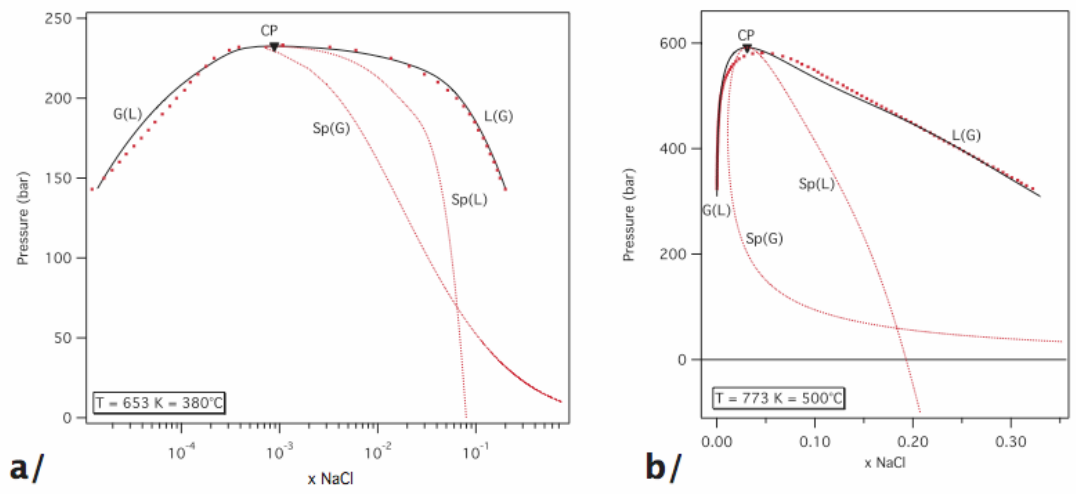

Fig. 7. Pressure- $\mathrm{NaCl}$ mole fractions diagrams of the $\mathrm{H}_{2} \mathrm{O}-\mathrm{NaCl}$ diagram, as calculated by the Anderko and Pitzer equation of state ${ }^{29}$. a/ At $653 \mathrm{~K}, 380^{\circ} \mathrm{C}$. b/ At $773 \mathrm{~K}, 500^{\circ} \mathrm{C}$.

Fig. 8 illustrates the metastability fields of the $\mathrm{H}_{2} \mathrm{O}-\mathrm{NaCl}$ system in a $P-T$ diagram by means of a series of spinodal isopleths calculated respectively for $x_{\mathrm{NaCl}}=0.01,0.03,0.05$ and 0.1 . Each isopleth depicts a loop, which is tangential to one point of the $\mathrm{H}_{2} \mathrm{O}-\mathrm{NaCl}$ critical curve. At this critical point, the nature of the isopleth changes from a liquid spinodal $S p(L)$ to a gas spinodal $S p(G)$. The diagram shows clearly that the addition of $\mathrm{NaCl}$ translates progressively the liquid spinodal curve $\mathrm{Sp}(\mathrm{L})$ to higher temperatures: e.g., the spinodal temperature at 1 bar increases from $320.45^{\circ} \mathrm{C}$ at $x_{\mathrm{NaCl}}=0$ to $403^{\circ} \mathrm{C}$ at $x_{\mathrm{NaCl}}=0.1$ (i.e. 26.5 $\mathrm{NaCl}$ wt \%, but in the stability field of halite). Hence, high concentrations of electrolytes favour the metastability of aqueous solutions. This conclusion is in agreement with experimental data of synthetized fluid inclusions of Shmulovich et al. ${ }^{7}$ or with the observed behaviour of natural hydrothermal systems involving the circulations of brines ${ }^{33}$.

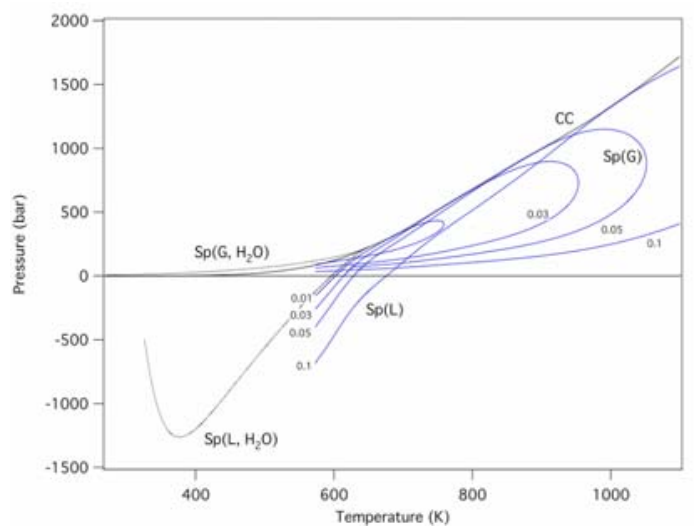

Fig. 8. Stability fields, calculated by the Anderko and Pitzer equation of state $\mathrm{e}^{29}$ of the $\mathrm{H}_{2} \mathrm{O}-\mathrm{NaCl}$ system in a pressure-temperature diagram. Solid lines: the saturation curve (LG) of pure water and 
the spinodal isopleths of $\mathrm{H}_{2} \mathrm{O}-\mathrm{NaCl}$ fluids (numbers refer to the mole fractions of $\mathrm{NaCl}$ ). Dotted lines: the liquid spinodal curve $\mathrm{Sp}\left(\mathrm{L}, \mathrm{H}_{2} \mathrm{O}\right)$ and gas spinodal curve $\mathrm{Sp}\left(\mathrm{G}, \mathrm{H}_{2} \mathrm{O}\right)$ of pure water.

\section{Geological implications}

This preliminary theoretical work can give some insights on the functioning of volcanic and hydrothermal systems. We shall mention here three application examples of eruptive phenomena, which are still poorly understood and need further investigations.

The first one is related to the Lake Nyos disaster (Cameroon) in 1986, which was produced by an explosive and massive release of $\mathrm{CO}_{2}$ from a crater lake and killed about 1700 people ${ }^{34,35}$. To explain this phenomenon, the preferred hypothesis amongst researchers is the model of a limnic eruption ${ }^{36}$, which results from the explosive $\mathrm{CO}_{2}$ exsolution of dormant supersaturated waters ${ }^{37}$ from the lake hypolimnion $\left(\mathrm{CO}_{2}\right.$-rich and dense lower layer) at a depth of $210 \mathrm{~m}^{35}$. The gas exsolution is supposed to release the pressure of the the water column, and thus to exert a positive feedback on further $\mathrm{CO}_{2}$ demixing, which would be able to create an overturn of lake waters and to sustain a steady gas flow ${ }^{37}$. However, the triggering mechanism is unknown (sinking of cold rain water, landslide, volcanic $\mathrm{CO}_{2}$ influx, etc ...). Moreover, such a model requires massive bubble nucleations and growths from the lake bottom. Fig. 3A suggests that a depressurization at the mild temperatures, which are typically found at the bottom (around 23 and $26^{\circ} \mathrm{C}^{38}$ ), might not be sufficient to generate such largescale bubblings. An additional constraint would be the occurence of higher temperatures (at least, above $150^{\circ} \mathrm{C}$, see Fig. 5). Such conditions could favour increasingly the intense $\mathrm{CO}_{2}$ exsolution and can easily by produced by injections of hydrothermal hot waters.

The second example is linked to phreato-magmatic eruptions, that appear to be predominant over basements constituted by finely porous formations like shales and siltstones ${ }^{39}$. This observation suggests that porosity may play an important role in the explosive behaviour of these boiling systems. The boiling in porous media can be described by ${ }^{40}$ :

$$
\mu_{i}^{\text {liquid }}\left(T, P_{\text {liquid }}\right)=\mu_{i}^{\text {gas }}\left(T, P_{\text {gas }}\right)
$$

where $\mu_{\mathrm{i}}^{\mathrm{k}}$ refers to the chemical potential of component $i\left(i=\mathrm{H}_{2} \mathrm{O}, \mathrm{CO}_{2}\right.$ or $\left.\mathrm{NaCl}\right)$ in the phase $k$. The capillary pressure $\Delta P=P_{\text {liquid }}-P_{\text {gas }}$ can be appreciated by a capillary equation, like the Laplace relation, which takes into account interfacial effects between the liquid wetting phase and the gas bubble. Fig. 9a displays the boiling curves calculated for different bubble radii with the Wagner and Pruss equation of state ${ }^{6}$, combined with the empirical relation of the same authors describing the temperature dependence of the liquid-gas interfacial tension. In this $P$ - $T$ plot, only the pressure-temperature properties of the liquid are drawn (the gas pressure is almost confounded with the saturation pressure of bulk water). Rigorously speaking, other effects, like solid-liquid-gas interactions or curvature effects should be allowed for, but this will not change the conclusions 
below. The main result of this diagram is that capillary forces shift liquid water into the metastable field of superheated waters. As a consequence, boiling in finely porous media is more prone to explosive reactions in the case of an external destabilization. An illustration of this aspect can be given in Fig. 9b, which displays a peperitic intrusion, i.e. a mixture of clasts and poorly consolidated wet sediments, into a lava flow (Pardines, $30 \mathrm{~km}$ south of ClermontFerrand, France). The injection of this peperitic dyke was permitted by the lower density of the peperite and the overpressure generated by the confinement of this boiling vapour-liquid-solid system. Remarkable facts are (1) the brecciated and altered aspect of the host basalt with radial and concentric joints separating rounded clasts, attesting pervasive percolation of steams, and (2) the subhorizontal apophyses, which developped at several levels from the peperites. These apophyses may be interpreted as successive steps of progression accelerations of the dyke. Thus, the intrusion was not a continuous phenomenon, but instead an alternance of (1) dormant, but recharging phase, where the peperite receives additional heat from the lava flow and (2) explosive boiling episode, providing the net impulse required to push the viscous basaltic flow. The finegrained peperitic matrix is rather mesoporous (pore diameters between $100 \mathrm{~nm}$ and $10 \mu \mathrm{m}$ ) and microporous (pore diameters below $100 \mathrm{~nm}$ ). Thus, according to Fig. 9a (shaded area), capillary effects are sufficient to generate capillary pressures between 0 and 10 bar (this latter value is commonly found in argillaceous and silty soils featured by low water contents). Note that the porosity of these natural materials is rather heterogeneous, defining a multitude of microsystems with different ebullition temperatures. Hence, destabilization of larger pores by an external perturbation (shock, lava displacement, ...) may trigger a positive feedback on the boiling of smaller pores and be at the origin of the chaotic behaviour of this small hydrothermal system.

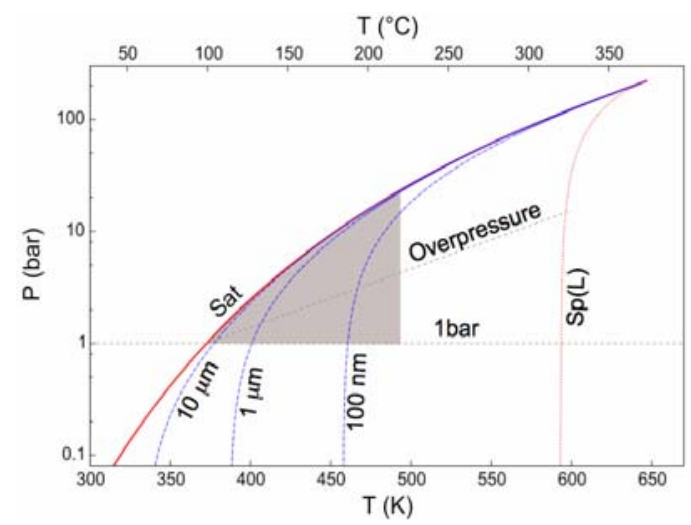

a)

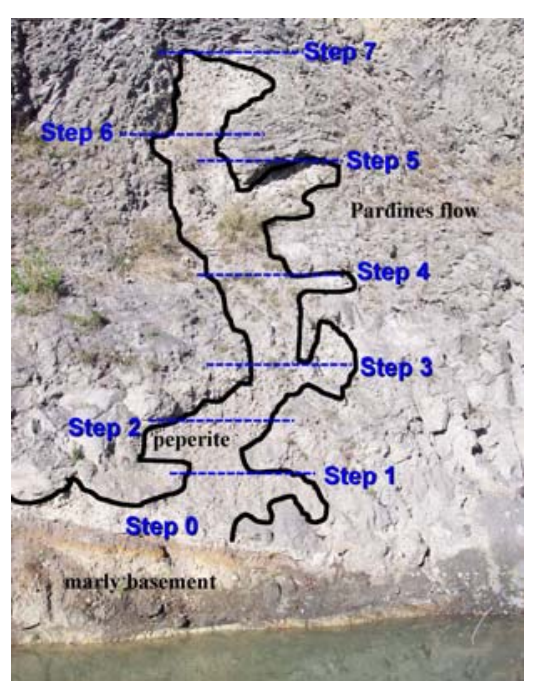

b) 
Fig. 9. a) A $P$-T diagram showing the boiling curves of adsorbed water in porous media (numbers refer to the radius of the pore). The dotted curve is the liquid spinodal curve $\mathrm{Sp}(\mathrm{L})$. b) The peperitic dyke in the lava flow of Pardines (the boundaries are outlined by the thick curve). The horizontal dashed lines indicate the positions of the successive growth pulses of the dyke.

The last application example is related to hydrothermal systems, sustained by a magmatic chamber, either in the oceanic lithosphere (at an accretion ridge ${ }^{41}$ ) or in a continental crust (e.g. a porphyry intrusion ${ }^{42}$ ). Fig. 10a displays the main parts of these systems, involving an upper brittle region overlying the ductile field. Both domains are featured by fundamental differences, which are summarized in Table 1. Of interest is the transition zone, which is characterized by a strong pressure gradient. As a consequence, a liquid, which has been exsolved by a magma, can follow here a depressurization path, cutting the $\mathrm{Sp}(\mathrm{L})$ liquid spinodal curve (see the $P-T$ diagram of Fig. 10b). Thus, it can boil explosively in a way, which is similar to BLEVE accidents in the industry ${ }^{11-18}$. Another case is the flushing out of pockets of aqueous solutions under pression (e.g. the "water sills" of Fyfe et al. ${ }^{43}$ ), which can lead also to superspinodal decompressions. Note that such explosive phenomena are not systematic, and depend on the initial salinity and the temperature of the fluid, as depicted in Fig. 10b. Nevertheless, this mechanism of explosive boiling play probably an important role in the brecciation of hydrothermal reservoirs.

\begin{tabular}{ccc}
\hline Properties & The ductile region & The brittle region \\
\hline Pressure regime & Lithostatic & Hydrostatic \\
Permeability & Low & High \\
Temperature range & $\geq 400^{\circ} \mathrm{C}$ & $100-360^{\circ} \mathrm{C}$ \\
Pressure range & $\geq 300 \mathrm{bar}$ & $1-300 \mathrm{bar}$ \\
Fluid connectivity & No & Yes \\
Main mechanism of & Conduction & Fluid advection \\
heat transport & & \\
\hline
\end{tabular}

Table 1. Main differences between the brittle zone and the ductile region of large hydrothermal systems. Pressure and temperature ranges are only indicative values. 

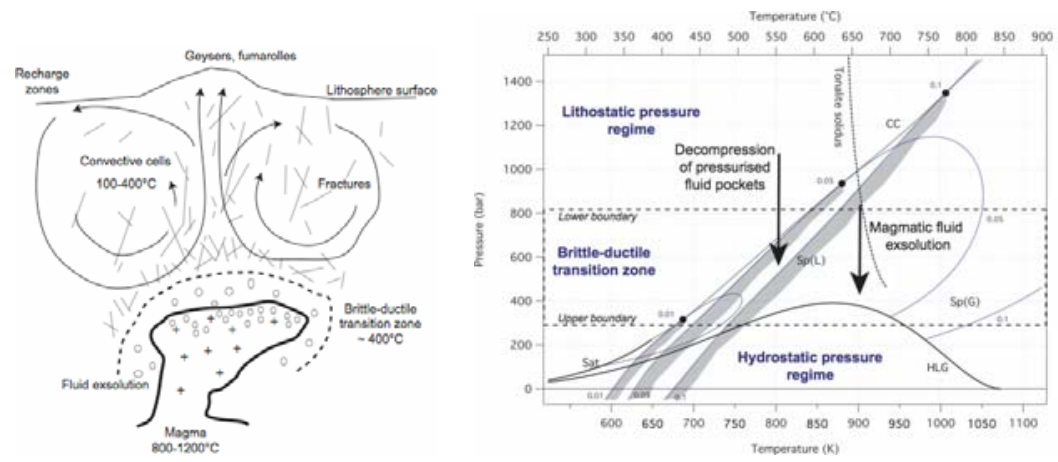

a)

b)

Fig. 10. a) Conceptual sketch of hydrothermal systems. b) $P-T$ diagram illustrating potentially explosive processes for the $\mathrm{H}_{2} \mathrm{O}-\mathrm{NaCl}$ in an hydrothermal environment (see text). Thick solid lines: the saturation curve for pure water (Sat) and the three-phase halite-liquid-vapour curve (HLG). Dotted line: the critical curve (CC). Thin solid lines: the spinodal curves for $x_{\mathrm{NaCl}}=0.01$ (3.2 wt \% $\mathrm{NaCl}), 0.05$ (14.6 wt \% NaCl) and $0.1(26.5 \mathrm{wt} \% \mathrm{NaCl})$ with their corresponding critical points (filled circles). The gray zones along liquid spinodal curves $\mathrm{Sp}(\mathrm{L})$ indicate the onset of the instability field of superheated $\mathrm{NaCl}$ aqueous solutions. The boundaries of the brittle-ductile transition zone have been drawn for a subvolcanic intrusion at $3 \mathrm{~km}$ below the topographic surface.

\section{Conclusion}

Spinodals represent an appealing concept, which allows to link the kinetics of physical transformations to the thermodynamic properties of the system. Explosive vaporizations can be identified as processes, which perturb a liquid up to near-spinodal singularities. This simple criteria, which is commonly applied by safety engineering in the industrial field, has been generalized here to the case of aqueous solutions. This modeling study shows the antagonist effects of dissolved volatiles and electrolytes: gaseous species tend to shift the explosivity conditions to lower temperatures, whereas dissolved salts tend to displace spinodal conditions to higher temperatures. As a result, this work can give useful indications to constrain the modeling of hydrothermal, phreatic and phreatomagmatic eruptions.

\section{Acknowledgements}

This work has been financially supported by the Agence Nationale de la Recherche (ANR) for the project SURCHAUF-JC05-48942.

\section{References}

1. Thiéry, R. and Mercury, L. (2009) Explosive properties of water in volcanic and hydrothermal systems. J. Geophys. Res. (accepted).

2. Debenedetti P.G. (1996) Metastable liquids. Concepts and principles. Princeton University Press, Princeton, NJ, 411 p.

3. Lasaga, A. (1998) Kinetic theory in the Earth Sciences. University Press, Princeton, NJ, 811 p. 
4. Rowlinson, J. and Swinton, F. (1982) Liquid and Liquid Mixtures. Butterworth Scientific, 3rd edition.

5. Imre, A. and Kraska, T. (2005) Stability limits in binary fluid mixtures. J. Chem. Phys. 122, 1-8.

6. Wagner, W. and Pruss, A. (2002) The IAPWS formulation 1995 for the thermodynamic properties of ordinary water substance for general and scientific use. J. Phys. Chem. Ref. Data 31, 387-535.

7. Shmulovich, K., Mercury, L., Thiéry, R., Ramboz, C. and El Mekki, M. (2009) Superheating ability of water and aqueous solutions. Experiments and geochemical consequences. Geochimica et Cosmochimica Acta (accepted).

8. Kiselev, S. (1999) Kinetic boundary of metastable states in superheated and stretched liquids. Physica A 269, 252-268.

9. Kiselev, S., and Ely, J. (2001) Curvature effect on the physical boundary of metastable states in liquids. Physica A 299, 357-370.

10. Debenedetti, P. (2000) Phase separation by nucleation and by spinodal decomposition: fundamentals. In: Kiran, E. et al. (eds), Supercritical Fluids, pp 123-166. Kluwer Academic Publishers, The Netherlands.

11. Abbasi, T. and Abbasi, S. (2007) The boiling liquid expanding vapour explosion (BLEVE): Mechanism, consequence assessment, management. Journal of Hazardous Materials 141, 480-519.

12. Casal, J., and Salla, J. (2006) Using liquid superheating for a quick estimation of overpressure in BLEVEs and similar explosions. Journal of Hazardous Materials A137, 1321-1327.

13. Planas-Cuchi, E., Salla, J., and Casal, J. (2004) Calculating overpressure from BLEVE explosions. Journal of Loss Prevention in the Process Industries 17, 431-436.

14. Pinhasi, G., Ullmann, A., and Dayan, A. (2007) 1D plane numerical model for boiling liquid vapor explosion (BLEVE). International Journal of Heat and Mass Transfer 50, 4780-4795.

15. Salla, J., Demichela, M., and Casal., J. (2006) BLEVE: a new approach to the superheat limit temperature. Journal of Loss Prevention in the Process Industries 19, 690-700.

16. Reid., R.C. (1979) Possible mechanism for pressurized-liquid tank explosions or BLEVE's. Science 203, 1263-1265.

17. Reid, R.C. (1976) Superheated liquids. Am. Scientist 64, 146-156.

18. Reid, R.C. (1983) Rapid phase transitions from liquid to vapor. Advances in Chemical Engineering 12, 105-208.

19. Corradini, M.L., Kim, B.J., and Oh, M.D. (1988) Vapor explosions in light water reactors: A review of theory and modeling. Progress in Nuclear Energy 22(1), 1-117.

20. Perfetti, E., Thiéry, R., and Dubessy, J. (2008) Equation of state taking into account dipolar interactions and association by hydrogen bonding. 
I- Application to pure water and hydrogen sulfide. Chem. Geol. 251, 58-66.

21. Perfetti, E., Thiéry, R., and Dubessy, J. (2008) Equation of state taking into account dipolar interactions and association by hydrogen bonding: II- Modelling liquid-vapour equilibria in the $\mathrm{H}_{2} \mathrm{O}-\mathrm{H}_{2} \mathrm{~S}, \mathrm{H}_{2} \mathrm{O}-\mathrm{CH}_{4}$ and $\mathrm{H}_{2} \mathrm{O}-\mathrm{CO}_{2}$ systems. Chem. Geol. 251, 50-57 (2008).

22. Stryjek, R. and Vera, J. (1986) An improved Peng-Robinson equation of state with new mixing rules for strongly non ideal mixtures. Can. J. Chem. Eng. 64, 334-340.

23. Stryjek, R. and Vera, J. (1986) PRSV2: a cubic equation of state for accurate vapour-liquid equilibrium calculations. Can. J. Chem. Eng. 64, 820-826.

24. Stryjek, R. and Vera, J. (1986) Vapour-liquid equilibria of hydrochloric acid and solutions with the PRSV equation of state. Fluid Phase Equilibria 25, 279-290.

25. Duan, Z. and Hu, J. (2004) A new cubic equation of state and its applications to the modeling of vapor-liquid equilibria and volumetric properties of natural fluids. Geochimica et Cosmochimica Acta 14, 2997-3009.

26. Thiéry, R. (1996) A new object-oriented library for calculating highorder multivariable derivatives and thermodynamic properties of fluids with equations of state. Computers \& Geosciences 22(7), 801-815.

27. Duan, Z. and Sun, R. (2003) An improved model calculating $\mathrm{CO}_{2}$ solubility in pure water and aqueous $\mathrm{NaCl}$ solutions from 273 to $533 \mathrm{~K}$ and from 0 to 2000 bar. Chem. Geol. 193, 257-271.

28. Asselineau, L., Bogdanic, G., and Vidal, J. (1979) A versatile algorithm for calculating vapour-liquid equilibria. Fluid Phase Equilibria 3, 273290.

29. Anderko, A. and Pitzer, K. (1993) Equation-of-state representation of phase equilibria and volumetric properties of the system $\mathrm{NaCl}-\mathrm{H}_{2} \mathrm{O}$ above 573 K. Geochimica et Cosmochimica Acta 57, 1657-1680.

30. Boublik, T. (1970) Hard sphere equation of state. J. Chem. Phys. 53, 471-472.

31. Stell, G., Rasaiah, J., and Narang, H. (1972) Thermodynamic pertubation theory for simple polar fluids. J. Mol. Phys. 23, 393-406.

32. Bischoff, J. (1991). Densities of liquids and vapors in boiling $\mathrm{NaCl}-\mathrm{H}_{2} \mathrm{O}$ solutions: A PVTX summary from 300 to $500^{\circ} \mathrm{C}$. Am. J. Sci. 291, 369381.

33. Orphanidis, E. (1995) Conditions physico-chimiques de précipitation de la barytine épigénétique dans le bassin sud-ouest de la fosse Atlantis II (Mer Rouge): données des inclusions fluides et approche expérimentale. Implications pour le dépôt des métaux de base et métaux précieux. Thèse Université d'Orléans, 180 p. 
34. Schenker, F. and Dietrich, V.J. (1986) The Lake Nyos gas catastrophe (Cameroon): a magmatological interpretation. Schweiz. Mineral. Petrogr. Mitt. 66, 343-384.

35. Evans, W.C. (1996) Lake Nyos: knowledge of the fount and the cause of disaster. Nature 379(6560), 21-22.

36. Zhang, Y. (1996) Dynamics of $\mathrm{CO}_{2}$-driven lake eruptions. Nature 379(6560), 57-59.

37. Rice, A. (2000) Rollover in volcanic crater lakes: a possible cause for Lake Nyos type disasters. J. Volcan. Geotherm. Res. 97, 233-239.

38. Kantha, L.H. and Freeth, S.J. (1996) A numerical simulation of the evolution of temperature and $\mathrm{CO}_{2}$ stratification in Lake Nyos since the 1986 disaster. J. Geophys. Res. 101(B4), 8187-8203.

39. Grunewald, U., Zimanowski, B., Büttner, R., Philipps, L.F., Heide, K. and Büchel, G. (2007) MFCI experiments on the influence of NaClsaturated water on phreato-magmatic explosions. J. Volc. Geotherm. Res. 159, 126-137.

40. Shapiro, A. and Stenby, E. (2001) Thermodynamics of the multicomponent vapor-liquid equilibrium under capillary pressure difference. Fluid Phase Equilibria 178, 17-32.

41. Nehlig, P. (1993) Interactions between magma chambers and hydrothermal systems: oceanic and ophiolitic constraints. J. Geophys. Res. 98(B11), 19621-19633.

42. Driesner, T. and Geiger, S. (2007) Numerical simulation of multiphase fluid flow in hydrothermal systems. Reviews in Mineralogy \& Geochemistry 65, pp 187-215.

43. Fyfe, W.S., Price, N.J. and Thompson, A.B. (1978) Fluids in the Earth's crust. Developments in Geochemistry 1, 383 pp., Elsevier Scientific, Amsterdam. 